\title{
Efficacy assessment of a nutraceutical with a marine protein complex in the reduction of female telogen effluvium
}

\begin{abstract}
Introduction: Telogen Effluvium may be related to the deficiency of certain nutrients such as iron, zinc, vitamins, essential fatty acids and proteins. Therefore, nutraceutical products could be used to treat potentially reversible Telogen Effluvium. In this work, the efficacy in increasing the number of hair fibers and reducing hair loss of a nutraceutical product containing proteins, marine extracts and a silica compound (ViviScal ${ }^{\circledR}$ ) was assessed. The study also aimed at the subjective evaluation of the product regarding the increase of hair and nails growth, improvement of skin appearance and quality of life, in general.
\end{abstract}

Materials and methods: The controlled, monocentric study was conducted during 6 months in volunteers with Telogen Effluvium. The efficacy assessment was performed by phototrichogram and by participants' opinion based on standardized questionnaires.

Results: There was a reduction in the number of telogen hair fibers and an increase in the number of total hair fibers in $83 \%$ of the participants after 6 months of treatment. The majority noticed an improvement in hair and nails growth and in skin appearance after 6 months of treatment.

Conclusion: The product was effective in increasing the total number of hair fibers and reducing Telogen Effluvium. This nutraceutical product was also positively evaluated by the participants regarding hair and nail growth, and skin appearance.
Volume I Issue 2 - 2017

\author{
Leila David Bloch, Cassiano Carlos \\ Escudeiro, Fernanda Daud Sarruf \\ IPclin Instituto de Pesquisa Clinica Integrada Ltda, Brazil
}

Correspondence: Leila David Bloch, IPclin Instituto de Pesquisa Clinica Integrada Ltda, 3 I 4 Rua Leonardo Cavalcante, |320|-0|3, Jundiai - SP, Brazil, Tel 55 || 4087-0092, Email leila@ipclin.com.br

Received: February 21, 2017 | Published: April 28, 2017

Keywords: nutrition, hair loss, phototrichogram, clinical trial

\section{Introduction}

Hair loss is a common complaint in dermatology clinics. The hair cycle is a complex biological process by which human hair follicles undergo three main stages: growth (anagen phase), apoptosisdriven regression (catagen phase) and the quiescent state (telogen phase). ${ }^{1}$ Telogen Effluvium can affect any age group and has several triggering factors. Among the main causes, can be mentioned: postpartum, thyroid diseases, stress, anemia and certain drugs, such as antineoplastic agents, among others..$^{2-5}$

Telogen Effluvium can also be related to nutritional deficiencies such as iron, zinc, vitamins, essential fatty acids and proteins. ${ }^{2-4,6}$ Thus, nutraceuticals can be used in the treatment of such potentially reversible Telogen Effluvium. A complex consisting of proteins, marine extracts and a silica compound (ViviScal $\AA$ ) has been studied for the treatment of hair disorders and showed efficacy in the treatment of androgenetic alopecia., ${ }^{7,8}$ Increasing in hair growth was also detected by digital photographs and self-assessment questionnaires of volunteers who took oral supplementation with Viviscal ${ }^{9}{ }^{9}$

The aim of this study was to investigate the efficacy of a nutraceutical containing the marine protein complex (Viviscal $\left.{ }^{\circledR}\right)$ in the treatment of Telogen Effluvium in female patients after a 6 months treatment, employing the phototrichogram technique, an objective method to evaluate hair scalp, ${ }^{10}$ and by the application of standardized questionnaires to assess the opinion of the participants.

\section{Materials and methods}

\section{Study design}

The study was controlled, monocentric, with duration of 6 months and was performed at Instituto de Pesquisa Clínica Integrada Ltda (IPclin Ltda), located in Sao Paulo-Brazil. The procedures were in accordance with ethical standards of the responsible committee on human experimentation and with the Helsinki Declaration..$^{11,12}$

\section{Research participants' selection}

Fifty-two female volunteers aged between 25 and 50 years, with phototypes II to IV ${ }^{13}$ were selected to participate in the study after signing the Informed Consent Form. The inclusion criteria were: Telogen Effluvium detected by clinical dermatological evaluation (positive traction test, moderate or strong); hair loss complaint; hair washing at least three times a week and healthy scalp skin. The adopted exclusion criteria were: Androgenetic Alopecia; use of hairpieces; history of allergy or irritation to the product's formula components; pregnancy; lactating; immunodeficiency; volunteers with kidney, heart or liver transplant; participants that performed hair straightening or relaxation procedures until 3 months before the study beginning; use of systemic or topical medications such as corticoids, anti-histamines, immunosuppressant, retinoids or medications that may interfere with the hair loss cycle. The participants were prohibited to alter diet, exercise and hygiene habits, as well as perform any procedure that may interfere with the hair loss cycle (e.g.: hair dye, straightening, 
etc.) and to use other products from the assessed category during the study.

\section{Investigational product and posology}

The nutraceutical investigational product Viviscal ${ }^{\circledR}$ Maximum Strength Oral Supplement (Lifes2good, Inc., Chicago, Illinois) was given to the volunteers, in a previously disguised packaging, to be used at home during 6 months. The participants were oriented to use two tablets a day during the main meals. Table 1 contains the product Viviscal ${ }^{\circledR}$ composition.

Table I Qualitative and quantitative composition of the investigational product Viviscal ${ }^{\circledR}$ maximum strength oral supplement

\begin{tabular}{ll}
\hline Components & Amount \\
\hline Accerola [Malphighia glabra] fruit blend powder & $33.33 \mathrm{mg}$ \\
$(25 \%$ Vitamin C) & \\
Ascorbic acid & $12.0 \mathrm{mg}$ \\
Marine protein complex & $450.0 \mathrm{mg}$ \\
Horsetail extract powder & $45.0 \mathrm{mg}$ \\
Millet dry extract & $7.50 \mathrm{mg}$ \\
D-biotin & $0.014 \mathrm{mg}$ \\
Zinc oxide & $3.90 \mathrm{mg}$ \\
Ferrous fumarate & $10.2 \mathrm{mg}$ \\
Nicotinamide & $6.20 \mathrm{mg}$ \\
\hline
\end{tabular}

\section{Assessments}

The determination of the efficacy of reducing hair loss was performed by questionnaire application to the participants and by phototrichogram. The assessments were performed in the inclusion day, and after three and six months of treatment. Medical assessments of clinical signs and questioning of discomfort sensations referred by the participants were performed every month during the study.

\section{Questioning of the participants}

The volunteers were questioned about the impact of hair appearance on their self-esteem and life quality at the beginning of the study (D0) and after 6 months of treatment (D180). Besides, they responded to a self-assessment questionnaire after 3 (D90) and 6 months of product usage (D180). The questions and answers of volunteers are presented in Table 3.

\section{Phototrichogram}

An area of approximately $2 \times 1 \mathrm{~cm}$ was selected on the right or left frontoparietal region of each volunteer, by the dermatologist. Then, the hair of the selected area was shaved until the shortest length possible. This shaving procedure was performed monthly to allow the analysis always to be performed on the same region along the study. After shaving, the region was photographed with a camera (Canon, model T3i) coupled with an optical accessory lens provided with own lighting. Two days after, the site was again photographed. This procedure was repeated after 3 and 6 months of treatment.

The images obtained at each experimental time were treated and analyzed by the program Image Pro Plus ${ }^{\circledR}$, version 6.0 , for total and telogen hair counting. The counting performed by the program was compared to the one performed manually by the dermatologist for results' validation. The product efficacy was determined based on the comparison of the total and telogen hair fiber counting at each experimental time, per volunteer. Statistical differences were assessed by paired t-test $(\alpha=0.05)$.

\section{Results and discussion}

Among the 52 selected participants, 35 completed the 6 months treatment with the investigational product. They were submitted to the medical assessment of clinical signs and discomfort sensations, to the efficacy assessment by phototrichogram and responded to an opinion questionnaire.

\section{Medical assessment of the product safety}

None of the 35 participants referred discomfort sensations with the product use and no clinical signs were detected due to the treatment.

\section{Phototrichogram}

Figure 1 represents an example of phototrichogram image obtained per experimental time. After analyzing the phototrichogram of the 35 participants we observed that: (1) 27 participants $(77 \%$ of the panel) presented reduction of the Telogen Effluvium after 3 months of treatment; (2) 25 (71\% of the panel) presented an increase in the total number of fibers in the assessed area after 3 months of treatment; (3) $29(83 \%$ of the panel) presented reduction of the Telogen Effluvium and an increase in the total number of fibers after 6 months of treatment. In Figure 2 the percentage of participants with a reduction of telogen hair and increase in the total number of hair fibers per experimental time is shown.

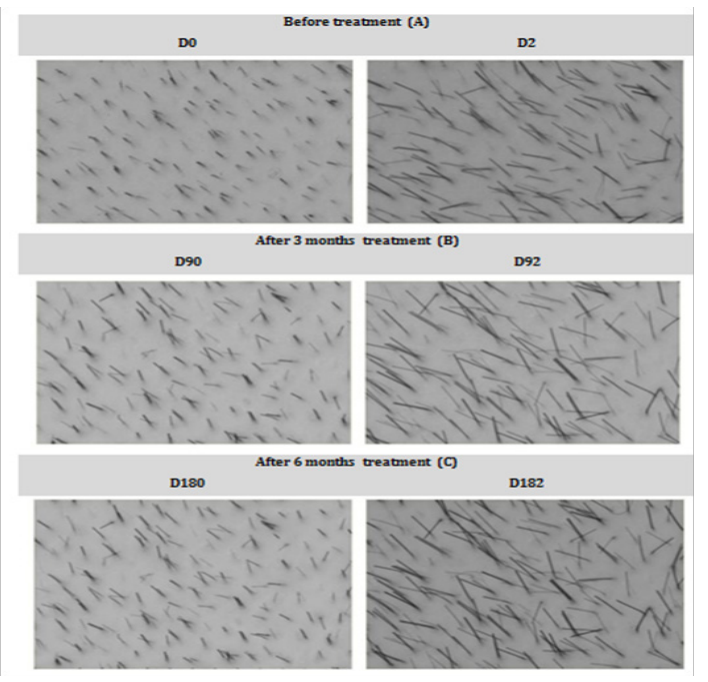

Figure I Phototrichogram obtained during treatment with Viviscal $\circledast$. Legend: Images obtained at the beginning of the study $(A)$ and after $3(B)$ and 6 months (C) of treatment.

The telogen fibers density reduced from 11.1 to $8.7 \mathrm{fibers} / \mathrm{cm}^{2}$ and total hair density increased from 110.1 to 118.0 fibers $/ \mathrm{cm}^{2}$ after 180 days treatment (Table 2). After 3 months treatment, participants presented $2.5 \%$ increase in the total number of fibers and $8.9 \%$ reduction in the number of telogen hair fibers. The percentage of telogen hair fibers in relation to the total number of fibers reduced $11.1 \%$. The efficacy was time-dependent since after 180 days of treatment, the total number of fibers increased $7.16 \%$, the reduction in the number of telogen hair fibers was $21.6 \%$ and the percentage of telogen fibers reduced $26.9 \%$. 
Table 2 Variation of telogen fibers density (a) and total hair density (b) after 90 and 180 days treatment. Legend: paired t-test statistical analysis was performed for times D0 and DI80 $(\alpha=0.05)$

\begin{tabular}{lllll}
\hline \multirow{2}{*}{ Parameter } & \multicolumn{2}{l}{ Time (days) } & & p-value \\
\cline { 2 - 4 } & D0 & D90 & D180 & -ver \\
\hline $\begin{array}{l}\text { Total Hair Density } \\
\begin{array}{l}\text { Telogen Fibers } \\
\text { Density }\end{array}\end{array}$ & $110.1 \pm 21.7$ & $112.9 \pm 21.0$ & $118.0 \pm 13.3$ & 0.01 \\
\hline
\end{tabular}

\section{Volunteers questioning}

The participants were questioned about the impact of hair appearance on their self-esteem and life quality before and after 6 months treatment. They also answered to a product efficacy evaluation questionnaire concerning hair, nails and skin after 3 and 6 months of product use.
The percentage of participants that responded each option to the assessed parameters for the questions concerning life quality is presented in Table 3. Based on the obtained answers we can claim that the volunteers' life quality improved with the treatment, as the favorability of the answers (\% of the answers "not at all" and "irrelevant") increased on D180 (after 6 months of treatment) when compared to D0 (before treatment).

The criterion to declare a certain answer as relevant in the selfassessment questionnaire was the association of the Top two boxes analysis with the Chi-Square statistic. The Top two boxes analysis considers the frequency of the favorable answers. Therefore, the parameter was considered relevant when at least $66 \%$ of the participants responded favorably to the question. Table 4 contains the list of the attributes that presented frequency of favorable responses above $66 \%$ per experimental time.

Table 3 Percentage of participant's answers to the attributes assessed on the life quality questionnaire before and after 6 months treatment

\begin{tabular}{|c|c|c|c|c|c|c|c|c|c|c|}
\hline \multirow{3}{*}{ Questions } & \multicolumn{10}{|c|}{ Percentage of participant's answers } \\
\hline & \multicolumn{2}{|c|}{ Too much } & \multicolumn{2}{|c|}{ A lot } & \multicolumn{2}{|c|}{ A little } & \multicolumn{2}{|c|}{ Not at all } & \multicolumn{2}{|c|}{ Irrelevant } \\
\hline & Do & D180 & D0 & D180 & D0 & D180 & D0 & D180 & D0 & D180 \\
\hline I am ashamed because of my thinning hair & 14 & 3 & 0 & 0 & 23 & 20 & 63 & 77 & 0 & 0 \\
\hline Because of my thinning hair I avoid social meetings & 3 & 0 & 0 & 3 & 11 & 3 & 86 & 94 & 0 & 0 \\
\hline $\begin{array}{l}\text { My condition stops me from eating or drinking on a social } \\
\text { event }\end{array}$ & 0 & 0 & 0 & 0 & 9 & 6 & 91 & 94 & 0 & 0 \\
\hline I avoid going out during the day because of my hair loss & 3 & 0 & 3 & 3 & 3 & 3 & 91 & 94 & 0 & 0 \\
\hline $\begin{array}{l}\text { My condition stops me from participating in sports } \\
\text { activities }\end{array}$ & 0 & 0 & 0 & 0 & 9 & 3 & 91 & 97 & 0 & 0 \\
\hline My condition affects my self-esteem & 20 & 0 & 3 & 6 & 29 & 29 & 49 & 66 & 0 & 0 \\
\hline I am less confident because of my condition & 3 & 0 & 3 & 3 & 17 & 9 & 77 & 89 & 0 & 0 \\
\hline $\begin{array}{l}\text { Because of my thinning hair, I fear to be the center of } \\
\text { attention }\end{array}$ & 3 & 0 & 3 & 3 & 6 & 3 & 89 & 94 & 0 & 0 \\
\hline $\begin{array}{l}\text { Because of my thinning hair, I am less extrovert than I } \\
\text { wanted to be }\end{array}$ & 3 & 0 & 0 & 3 & 3 & 0 & 94 & 97 & 0 & 0 \\
\hline $\begin{array}{l}\text { Because of my thinning hair I have problems in my } \\
\text { intimacy }\end{array}$ & 6 & 0 & 0 & 0 & 3 & 6 & 91 & 94 & 0 & 0 \\
\hline
\end{tabular}

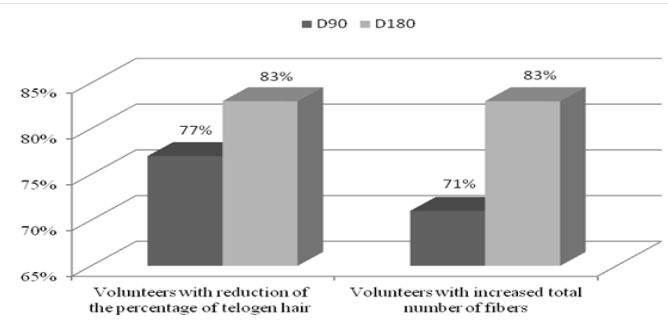

Figure 2 Percentage of participants with an improvement concerning the attributes referred to the Phototrichogram analysis - reduction of the percentage of telogen hair and increase in the total number of fibers.

Telogen Effluvium may be caused, among other factors, by nutritional deficiencies, for example, iron, zinc, proteins, vitamins, etc.. ${ }^{2,6,14-16}$ Hair exerts a great impact on the self-esteem and life quality of the population, although it does not possess a vital function. ${ }^{15}$ For this reason, the development of nutraceutical products with proven efficacy and safety for hair loss treatment is of utmost importance.
Table 4 Attributes with favorable answers above $66 \%$ for the assessment times D90 and DI80, referring to the self-assessment questionnaire. Legend: The parameter did not obtain favorable responses above $66 \%$ for this evaluation time; $\mathrm{D} 90=3$ months treatment; $\mathrm{DI} 80=6$ months treatment

\begin{tabular}{lll}
\hline ATTRIBUTE & D90 & D180 \\
\hline General hair volume & $/$ & $94 \%$ \\
Scalp coverage & $/$ & $81 \%$ \\
Hair thickness & $75 \%$ & $92 \%$ \\
Hair smoothness & $86 \%$ & $97 \%$ \\
Gloss & $86 \%$ & $100 \%$ \\
Nail strength & $78 \%$ & $92 \%$ \\
Nail growth rate & $69 \%$ & $91 \%$ \\
Skin moisture & $/$ & $86 \%$ \\
Face wrinkles & $/$ & $74 \%$ \\
Skin softness & $69 \%$ & $92 \%$ \\
Skin elasticity & $/$ & $69 \%$ \\
Skin smoothness & $75 \%$ & $92 \%$ \\
Healthy skin & $81 \%$ & $94 \%$ \\
Considering all effects & & \\
observed on my hair, nails and & $94 \%$ & $100 \%$ \\
skin, may I claim to be happy & & \\
with the treatment? & &
\end{tabular}


The selected phototrichogram technique was adopted because it is not invasive and it does not cause any discomfort for the volunteers. It also allows obtaining images with high resolution, thus enabling a greater reliability in anagen and telogen hair counting. ${ }^{17}$ On this study, we found that the investigational product Viviscal ${ }^{\circledR}$ was considered safe and effective to reduce Telogen Effluvium. None of the study participants presented topical or systemic adverse reactions to the treatment. We also observed a time-dependent efficacy of the nutraceutical product on the objective assessment by phototrichogram after 3 and 6 months of treatment, as around $70 \%$ of the participants reacted to the treatment after 3 months and around $80 \%$ after 6 months. After 180 days treatment, the total number of fibers increased $9.3 \%$, the reduction in the number of telogen hair fibers was $19.6 \%$ and the percentage of telogen hair fibers reduced $25.6 \%$.

In addition to the objective assessment, we also performed the nutraceutical product's subjective efficacy evaluation by opinion questioning to the research participants. In this assessment, the product was positively evaluated by the majority of the volunteers regarding the improvement of life quality and parameters related to hair, skin and nails aspect. By the end of the 6 months treatment, $100 \%$ of the assessed participants claimed to be satisfied with the treatment's effects.

Scientific papers demonstrated that Viviscal ${ }^{\circledR}$ supplementation was effective in the treatment of androgenic alopecia in young males, ${ }^{8}$ was useful for premenopausal women to deal with subclinical hair thinning or hair loss conditions ${ }^{18}$ and to promote hair growth in adult women with self-perceived thinning hair, according to visual analysis. ${ }^{919}$ However, the phototrichogram technique followed by the image analysis using the software Image Pro Plus ${ }^{\circledR}$ seems more appropriate than visual analysis because it allowed obtaining objective and accurate results.

\section{Discussion}

The Nutraceuticals Viviscal ${ }^{\circledR}$ Maximum Strength Oral Supplement contains acerola fruit blend powder (25\% vitamin C), ascorbic acid, AminoMar CTM marine protein complex, a form of silica derived from Equisetum sp. (horsetail), millet dry extract, D-biotin, zinc oxide, ferrous fumarate, and nicotinamide. Nutritional factors such as vitamins and hair loss are highly related. Biotin (vitamin $\mathrm{H}$ or B7) is a vitamin that participates as a cofactor in several metabolic pathways, as gluconeogenesis, fatty acid synthesis, and amino acid catabolism. Biotin deficiency is related with neurological manifestations, skin rash, hair loss. ${ }^{15,20}$ Vitamin $\mathrm{C}$ (ascorbic acid) is essential for collagen synthesis and cross-linkage of keratin fibers. ${ }^{6}$

Zinc is an essential element required by several enzymes and different conditions may affect its absorption and excretion by human body. ${ }^{16}$ Zinc deficiency is associated with alopecia, hair dryness, brittleness and patients usually responds well to supplementation treatment. ${ }^{16,21}$ There is no consensus about the relationship between iron deficiency and diseases like alopecia areata, androgenetic alopecia, Telogen Effluvium, and diffuse hair loss, ${ }^{22}$ but some clinical trials showed that iron supplementation reduced Telogen Effluvium. ${ }^{23}$

The AminoMar CTM marine protein complex from Viviscal ${ }^{\circledR}$ is composed of a blend of shark powder and mollusk powder, both derived from sustainable marine sources, rich in proteins and glycosaminoglycans of marine origin. Although the exact mechanism of this product is unknown, the reason for the results may be related to greater bioavailability of polysaccharide complexes when compared with similar products. Also, the product may enhance the proliferation of dermal papillae cells, which presents an important role in hair growth cycle. ${ }^{24}$ As the marine protein complex, the silica is a key component because it is associated with the strengthening of hair. Silica can help to prevent baldness because it stimulates hair growth. ${ }^{25}$

\section{Conclusions}

The investigational product ViviScal ${ }^{\circledR}$ was effective to reduce the Telogen Effluvium and to increase the total number of hair fibers after 3 and 6 months of treatment. The treatment was positively evaluated by the study participants regarding the hair growth, nail growth, skin appearance and life quality.

\section{Acknowledgements}

The research was funded by Lifes2good.

\section{Statement of ethics}

The study procedures were in accordance with ethical standards of the responsible committee on human experimentation and with the Helsinki Declaration.

\section{Conflict of interest}

The author declares no conflict of interest.

\section{References}

1. Mirallas O, Grimalt R. The postpartum telogen effluvium fallacy. Skin Appendage Dosrd. 2015;1(4):198-201.

2. Olsen E. Hair Fitzpatrick's dermatology. In Freedberg I, et al. editors. General Medicine. New York, USA: McGraw-Hill; 2003. p. 633-655.

3. Sinclair R, Patel M, Dawson-Junior T, et al. Hair loss in women: medical and cosmetic approaches to increase scalp hair fullness. Br J Dermato. 2011;165(s3):12-18.

4. Rossi A, Priolo L, Iorio A, et al. Evaluation of a therapeutic alternative for telogen effluvium: a pilot study. J Cosmet Dermatological Sci Appl. 2013;3(3A):9-16.

5. La Placa M, Balestri R, Bardazzi F, et al. Scalp psoriasiform contact dermatitis with acute telogen effluvium due to topical minoxidil treatment. Ski Appendage Disord. 2015;1(3):141-143.

6. Finner A. Nutrition and hair: deficiencies and supplements. Dermatol Clin. 2013;31(1):167-172.

7. Thom E. Efficacy and tolerability of Hairgain in individuals with hair loss: a placebo-controlled, double-blind study. J Int Med Res. 2001;29(1):2-6.

8. Lassus A, Eskelinen E. A comparative study of a new food supplement, ViviScal ${ }^{\circledR}$, with fish extract for the treatment of hereditary androgenic alopecia in young males. $J$ Int Med Res. 1992;20(6):445-453.

9. Ablon G. A Double-blind, placebo-controlled study evaluating the efficacy of an oral supplement in women with self-perceived thinning hair. $J$ Clin Aesthetic Dermatology. 2012;5(11):28-34.

10. Van Neste D. Female patients complaining about hair loss: documentation of defective scalp hair dynamics with contrast-enhanced phototrichogram. Ski Res Technol. 2006;12(2):83-88.

11. http://conselho.saude.gov.br/resolucoes/2012/Reso466.pdf

12. http://www.prefeitura.sp.gov.br/cidade/secretarias/upload/saude/arquivos/ comiteetica/Reso196 English.pdf 
13. Fitzpatrick T. The validity and practicality of sun-reactive skin types I through VI arch dermatol. Arch Dermatol. 1988;124(6):869-871.

14. Lengg N, Heidecker B, Seifert B, et al. Dietary supplement increases anagen hair rate in women with telogen effluvium: results of a doubleblind, placebo controlled trial. Futur Med. 2007;4(1):59-65.

15. Rushton D. Nutritional factors and hair loss. Clin Exp Dermatol. 2002;27(5):396-404.

16. Goldberg L, Lenzy Y. Nutrition and hair. Clin Dermatol. 2010;28(4):412419 .

17. Dhurat R, Saraogi P. Hair evaluation methods: merits and demerits. Int J Trichology. 2009;1(2):108-119.

18. Rizer R, Stephens T, Herndon J, et al. A marine protein-based dietary supplement for subclinical hair thinning/loss: Results of a multisite, double-blind, placebo-controlled clinical trial. Int $J$ Trichology. 2015;7(4):156-166.

19. Ablon G. A 3-Month, Randomized, double-blind, placebo-controlled study evaluating the ability of an extra-strength marine protein supplement to promote hair growth and decrease shedding in women with self-perceived thinning hair. Dermatol Res Pract. 2015;2015:841570.

20. Gravel R, Narang M. Molecular genetics of biotin metabolism: old vitamin, new science. J Nutr Biochem. 2005;16(7):428-431.
21. Neve H, Bhatti W, Soulsby C, et al. Reversal of hair loss following vertical gastroplasty when treated with zinc sulphate. Obes Surg. 1996;6(1):63-65.

22. Trost L, Bergfeld W, Calogeras E. The diagnosis and treatment of iron deficiency and its potential relationship to hair loss. $\mathrm{I}$ Am Acad Dermatol. 2006;54(5):824-844.

23. Rushton D, Norris M, Dover R, et al. Causes of hair loss and the developments in hair rejuvenation. Int J Cosmet Sci. 2002;24(1):17-23.

24. Ablon G, Dayan S. A Randomized, Double-blind, placebo-controlled, multi-center, extension trial evaluating the efficacy of a new oral supplement in women with self-perceived thinning hair. J Clin Aesthetic Dermatology. 2015;8(12):15-21.

25. Vasanthi N, Saleena L, Raj S. Silicon in day today life. World Appl Sci J. 2012;17(11):1425-1440. 